\title{
Dinámica microbial del suelo asociada a diferentes estrategias de manejo de Phytophthora cinnamomi Rands en aguacate
}

\author{
Joaquín Guillermo Ramírez Gil', Dario Antonio Castañeda Sánchez², Juan Gonzalo Morales Osorio ${ }^{3}$
}

\section{RESUMEN}

La marchitez del aguacate es la enfermedad más limitante de este cultivo, cuyo agente causal más relevante es el oomycete Phytophthora cinnamomi Rands. Es por esto que se han desarrollado diferentes estrategias para su manejo integrado, pero aún prevalece el uso de productos químicos, como única medida de manejo, generando impactos negativos en el ambiente y la salud. Uno de los efectos perjudiciales que se ocasiona es la alteración de las poblaciones microbianas en el suelo. Este trabajo estuvo encaminado a conocer la dinámica microbiana del suelo, bajo diferentes estrategias de manejo de esta enfermedad, para lo cual se midió su dinamismo mediante unidades formadoras de colonias (UFC), para hongos, bacterias y actinomicetos, a partir de muestras de suelo y rizósfera de la raíz, bajo incubación en condiciones de anaerobiosis y aerobiosis, además se midió la actividad microbiana total, en condiciones de laboratorio, como complemento se cuantificaron microorganismos como: Trichiderma spp, bacterias formadoras de endosporas (BAFE), celulolíticos, proteolíticos, amilolíticos, solubilizadores de fosfato, fijadores asimbióticos de nitrógeno y promotores del crecimiento, como Pseudomonas spp., fluorescentes. Los resultados encontrados en esta investigación, sugieren que el uso individual y combinado de mantillo orgánico, material compostado de estiércol bovino, enmienda mineral y cascarilla de arroz y la propuesta de integración; incrementan significativamente la población y actividad microbiana aerobia, en la cual se identificaron microorganismos antagonistas como, Trichiderma spp., celulolíticos, Pseudomonas spp. fluorescentes y BAFE.

Palabras claves: marchitez del aguacate (Persea americana Mill.), población microbiana en raíz, manejo integrado.

\section{RESUMO}

\section{Dinâmica microbiana do solo associada a diferentes estratégias de manejo de Phytophthora cinnamomi Rands em abacateiro}

A podridão das raízes do abacateiro é a principal doença dessa cultura, sendo seu agente etiológico o Phytophthora cinnamomi Rands. Por isso, tem-se desenvolvido diferentes estratégias para seu manejo integrado, mas ainda prevalece o uso de produtos químicos como única medida de controle, causando impactos negativos no ambiente e na saúde. Um dos efeitos prejudiciais ocasionados é a alteração das populações microbianas no solo. Sendo assim, este trabalho teve como objetivo estudar a dinâmica microbiana do solo em diferentes estratégias de manejo da doença, medindo sua dinâmica mediante a quantificação de unidades formadoras de colônias (UFC) de fungos, bactérias e actinomicetos a partir de amostras de solos e da rizosfera, sob incubação em condições de anaerobiose e aerobiose e medindo-se a atividade microbiana total no laboratório. Complementarmente, foram identificados microrganismos

\footnotetext{
Enviado el 14/12/2012 y aprobado el 18/07/2013.

'Ingeniero Agrónomo. Departamento de Ciencias Agronómicas, Universidad Nacional de Colombia, sede Medellín, Campus El Volador, Bloque 11, A.A, 1779, Medellín, Colombia. jgramireg@unal.edu.co

2Ingeniero Agrónomo, PhD. Departamento de Ciencias Agronómicas, Universidad Nacional de Colombia, sede Medellín, Campus El Volador, Bloque 11, A.A, 1779, Medellín, Colombia. dacastanedas@gmail.com

${ }^{3}$ Ingeniero Agrónomo, PhD. Profesor Asociado, Departamento de Ciencias Agronómicas, Universidad Nacional de Colombia, sede Medellín, Campus El Volador, Bloque 11, A.A, 1779, Medellín, Colombia.jgmoraleso@unal.edu.co (autor para correspondencia).

Este trabajo hace parte de la Tesis de Maestría del primer autor.
} 
como Trichoderma spp, bactérias formadoras de endósporos (BAFE), celulolíticos, proteolíticos, amilolíticos, solubilizadores de fosfatos, fixadores assimbióticos de nitrogênio e promotores de crescimento como Pseudomonas spp, fluorescentes. Os resultados encontrados nesta pesquisa sugerem que o uso combinado de camada de matéria orgânica, material compostado de esterco bovino, corretivo mineral e casca de arroz e a proposta de integração, aumentam significativamente a população e a atividade microbiana aeróbia na qual foram identificados microrganismos antagonistas como, Trichoderma spp., celulolíticos, Pseudomonas spp. fluorescentes e BAFE.

Palavras-chave: podridão de raízes do abacateiro (Persea americana Mill.), população microbiana em raiz, manejo integrado.

\section{INTRODUCCIÓN}

La microbiota del suelo, puede servir como un bioindicador de la salud de los ecosistemas y agroecosistemas, reflejando el efecto de los procesos agrícolas y el manejo de los recursos vegetales sobre este componente, afectando tanto su biodiversidad, como la densidad de las poblaciones microbianas (Buckley \& Schmidt, 2003; Girvan et al., 2004; Ariena et al., 2006). Estas variables pueden verse reducidas por el efecto de las prácticas agrícolas basadas en productos químicos y pueden recuperarse con medidas como la aplicación de algunas fuentes de materia orgánica (Richter et al., 2011; Bonilla et al., 2012).

El estudio de la microbiota del suelo cobra mayor importancia en el complejo marchitez del aguacate debido a que en esta patología pueden estar implicados agentes causales de tipo biótico y abiótico, siendo el Oomycete Phytophthora cinnamomi Rands el más relevante, el cual puede causar pérdidas económicas considerables, al no realizar un correcto manejo de esta enfermedad, donde se deben buscar medidas amigables con el medio ambiente tratando de generar el menor desequilibrio en los agroecosistemas (Pérez, 2008; Richter et al., 2011; Bonilla etal., 2012).

En los suelos existe una gran diversidad de microorganismos que podrían presentar potencial antagónico o de supresión sobre P. cinnamomi. Los trabajos realizados sugieren que la actividad positiva de estas poblaciones de microorganismos, podría activarse mediante el uso de coberturas o enmiendas orgánicas (Broadbent \& Baker, 1974; Richter et al., 2011; Bonilla et $a l ., 2012)$. El efecto directo de algunos microorganismos sobre $P$. cinnamomi, se debe a la reducción de la liberación de zoosporas, movimiento de estas, incremento de la lisis de las paredes celulares e inhibición de la producción de esporangios (Broadbent \& Baker 1974; Costa et al., 2000; Downer et al., 2001).

P. cinnamomi se ha estudiado por más de 60 años, como resultado de este proceso se han generado estrategias eficientes y ambientalmente amigables, pero su manejo se ha reducido casi que exclusivamente al uso de productos químicos, aumentando así la contaminación del suelo y la presión de selección sobre las poblaciones de este Oomyceto (Pérez, 2008). Existen muchos reportes de búsqueda de resistencia genética, prácticas culturales, microbiológicas, y el uso de fungicidas, para disminuir el efecto negativo que causa P. cinnamomi en Persea americana Mill (Broadbent \& Baker, 1974; Pérez, 2008; Richter et al., 2011).

Esta investigación tuvo como objetivo la evaluación de la dinámica de microorganismos del suelo en un lote cultivado de aguacate bajo diferentes estrategias de manejo de la marchitez del aguacate causada por $P$. cinnamomi.

\section{MATERIALES Y MÉTODOS}

\section{Localización}

Este trabajo se desarrolló en un lote de 4 ha sembrado con P. americana cv Hass de seis años de edad a una distancia de $7 \times 7 \mathrm{~m}$, ubicado en el municipio de Donmatías, Antioquia-Colombia $\left(6^{\circ} 27^{\prime} 54.47^{\prime \prime} \mathrm{N}-75^{\circ} 24^{\prime} 45.42^{\prime \prime} \mathrm{O}-2379\right.$ m), a una altura de $2379 \mathrm{msnm}, 2500 \mathrm{~mm}$ de precipitación promedio anual, clasificado como zona de vida bosque muy húmedo montano bajo (bmh-MB) sensu Holdridge (Holdridge, 1967). Las evaluaciones se realizaron desde junio del 2009 hasta mayo del 2012.

\section{Diagnóstico de la enfermedad y manejo agronómico de plantas en el lote}

Para cada árbol con síntomas se verificó la infección con $P$. cinnamomi a partir de muestras de raíces afectadas. En laboratorio éstas se lavaron con agua, se seccionaron $\left(0.5 \mathrm{~cm}^{3}\right)$ y desinfestaron superficialmente con etanol $(70 \%)$ por $30 \mathrm{~s}$, seguido de un lavado en agua destilada estéril por $30 \mathrm{~s}$, después se sumergieron en hipoclorito de sodio (3\%) por $30 \mathrm{~s}$ y por último se lavaron con agua destilada estéril por $30 \mathrm{~s}$. De las muestras desinfestadas se cortaron trozos de $3 \mathrm{~mm}^{3}$ y se realizó la siembra en medios selectivos V8-PARPH y V8-NARPH (Hardham, 2005). Las colonias obtenidas se identificaron con base en las claves 
taxonómicas reportadas por Hardham (2005). El diagnóstico se corroboró en un laboratorio privado mediante pruebas serológicas. En todas las plantas se realizaron labores tradicionales del cultivo como manejo de plagas, arvenses, enfermedades foliares, fertilizaciones periódicas, poda y drenajes externos.

\section{Tratamientos evaluados}

Se evaluaron ocho estrategias usadas en el manejo de la enfermedad y un control, los tratamientos fueron: T0: Control (plantas enfermas); T1: aspersión al suelo y alrededor de la gotera (sobre un radio de $2 \mathrm{~m}$ ) del árbol de 10 L de metalaxyl + mancozeb (Ridomil Gold®) a una concentración de $3.75 \mathrm{~g}$ de producto comercial por litro de agua; T2: inyecciones al tallo de cada planta de $7 \mathrm{~mL}^{3}$ de fosfito de potasio (Agrifos ${ }^{\circledR}$ ); T3: aplicación simultanea de los tratamientos T1 y T2; T4: aspersión al suelo y alrededor de la gotera del árbol (sobre un radio de $2 \mathrm{~m}$ ) de $10 \mathrm{~L}$ de silicato de potasio $\left(20.5 \% \mathrm{SiO}_{2}, 8.0 \% \mathrm{~K}_{2} \mathrm{O}\right)$, a una concentración de $20 \mathrm{~mL}$, de producto comercial (silicato de potasio $\left.{ }^{\circledR}\right)$ por litro de agua; T5: adición en el área de influencia de la raíz (sobre un radio de $2 \mathrm{~m}$ ) de una capa de $10 \mathrm{~cm}$ de espesor de mantillo orgánico (residuos de Pennisetum clandestinum; Cynodon plectostachium; P. americana; Pteridium aquilinum y hojas de Acacia melanoxylon, en partes iguales); T6: incorporación, alrededor del área de influencia de la raíz, de $10 \mathrm{~kg}$ de un sustrato compostado compuesto por estiércol bobino, cascarilla de arroz y enmienda mineral $\left(\mathrm{P}_{2} \mathrm{O}_{5}, 13 \% ; \mathrm{CaO}\right.$, $25 \% ; \mathrm{MgO}, 7 \% ; \mathrm{S}, 10 \% ; \mathrm{SiO}_{2}, 6 \%$ ), en relación gravimétrica de 1.25:0.5:0.25 respectivamente; T7: aplicación simultanea de los tratamientos T4+T5+T6; T8: aplicación simultánea de los tratamientos $\mathrm{T} 1+\mathrm{T} 2+\mathrm{T} 4+\mathrm{T} 5+\mathrm{T} 6$. Se hicieron tres ciclos mensuales continuos de los tratamientos $\mathrm{T} 1, \mathrm{~T} 2$, T3, T4 y T6; para el tratamiento T5, se hicieron tres aplicaciones en el tiempo, espaciadas cada 1.5 meses y tres ciclos de $\mathrm{T} 7$ y $\mathrm{T} 8$.

\section{Variables evaluadas \\ Desarrollo de la enfermedad}

El seguimiento del desarrollo de la enfermedad se realizó cada dos meses, midiendo la severidad de la enfermedad en cada planta evaluada, según la escala reportada por Coffey, (1991). Con los datos obtenidos se calculó el área bajo la curva de progreso de la enfermedad (ABCPE) (Madden et al., 2007).

\section{Microbiota evaluada}

Las evaluaciones se hicieron en el período comprendido entre noviembre del 2009 y mayo del 2012. Se tomaron muestras compuestas de suelo colectadas en los primeros $30 \mathrm{~cm}$ de profundidad, sobre la zona de influencia de la gotera del árbol (sobre un diámetro de 2 m) en cada una de las unidades experimentales y de la zona cercana a la rizosfera $(2 \mathrm{ml})$. Sobre estas muestras se midieron las unidades formadoras de colonia (UFC) de hongos, bacterias y actinomicetos mediante la técnica de dilución en placa Petri por recuento directo siguiendo las indicaciones de Madigan et al. (2004). Las bacterias fueron evaluadas en medio agar nutritivo (AN), $\mathrm{pH}$ : 6 , durante 48 horas a $28^{\circ} \mathrm{C}$, con adición de benomil (Benlate $\left.{ }^{\circledR}\right)\left(75 \mathrm{mg} \mathrm{L}^{-1}\right)$. Los hongos se evaluaron en medio papa dextrosa agar (PDA), pH 5,0, ajustado con ácido láctico y suplementado con sulfato de estreptomicina (100 $\left.\mathrm{mg} \cdot \mathrm{L}^{-1}\right)$ y cloramfenicol $\left(30 \mathrm{mg} \cdot \mathrm{L}^{-1}\right)$; la incubación se realizó durante 6 días a $25^{\circ} \mathrm{C}$. Para la evaluación de actinomicetos se utilizó el medio almidón-caseína (AC) suplementado con fluconazol al $0.25 \%$, incubándose a $28^{\circ} \mathrm{C}$ por un período de 10 días. El crecimiento en medio de cultivo se realizó en condiciones de aerobiosis y de anaerobiosis; para esta última se utilizó una cámara de vacío, donde previamente se realizó el agotamiento del oxígeno por combustión. Con base en las características morfológicas de todos los microorganismos recuperados en las distintas condiciones, se definieron diferentes morfotipos, con los datos obtenidos se calcularon los índices de diversidad de Shannon, de riqueza de Margalet y de equidad (equitability), usando el programa PAST versión 2.16, para toda la población de microorganismos (Hammer et al., 2001). La actividad microbiana total se midió mediante la técnica de respirometría en condiciones de laboratorio (Anderson \& Domsch, 1978).

\section{Evaluación de grupos funcionales}

Para la evaluación de las Pseudomonas spp. fluorescentes se utilizó el medio B de King (King et al., 1954), suplementado con los antibióticos ampicilina (50 $\left.\mathrm{mg} \mathrm{L}^{-1}\right)$ y cloranfenicol (12.5 $\mathrm{mg} \mathrm{L}^{-1}$ ) (Simon \& Ridge, 1974). El crecimiento de los microorganismos celulíticos (CL), amilolíticos (AM), quitinolíticos (QU) y proteolíticos (PT), se desarrolló siguiendo las indicaciones de Wood (1980). Los microorganismos solubilizadores de fosfato se evaluaron según el protocolo descrito por Osorio \& Habte (2001). Los microorganismos fijadores asimbióticos de nitrógeno, fueron evaluados según la metodología reportada Ramirez por Dobereiner \& Day (1976). La selección de las bacterias aeróbicas formadoras de espora (BAFE), se hizo sometiendo las diluciones $10^{-2}$ y $10^{-6}$ de suelo en agua a $80^{\circ} \mathrm{C}$ durante 15 minutos al baño maría y sembrándolas en medio TSA, con adición de Benlate ${ }^{\circledR}$ (75 mg L-1) (Ramírez, 2005). Los hongos del género Thichoderma spp., se aislaron en medio de cultivo PDA, suplementado con $0.5 \%$ de Igepal (Sigma, St Louis, USA) (Porras et al., 2007). Todos los microorganismos pertenecientes a los grupos funcionales se incubaron a $28^{\circ} \mathrm{C}$, con 12 horas de luz y 12 de oscuridad, por periodos 
de tiempo comprendidos entre 3-10 días. Después de la incubación se hizo el recuento de UFC, para todos los grupos y se hicieron los estimativos de las poblaciones por gramo de suelo seco (UFC g ${ }^{-1}$ de suelo). En el caso de las Pseudomonas spp. fluorescentes, se contabilizaron solo las colonias productoras de pigmentos fluorescentes bajo luz ultravioleta (260 nm) (Ramírez, 2005). Los promedios obtenidos para cada grupo de microorganismos se separaron mediante la prueba de Tukey como se describe a continuación.

\section{Análisis estadístico}

Se seleccionó como unidad experimental un árbol de seis años de edad con estado de desarrollo de la enfermedad en nivel 2 (Coffey, 1991). Se evaluaron 5 repeticiones por cada tratamiento, las cuales se ubicaron en 5 bloques, considerando como criterio de bloqueo la pendiente del terreno. Se probó para cada una de las variables evaluadas, la homocedasticidad y normalidad $(P<0.01)$, utilizando los criterios de Levene y Kolmogorov-Smirnov, respectivamente. Corroborado estos principios se realizó un análisis de varianza y una prueba de separación de medias de Tukey con un nivel de significancia del $99 \%$.

\section{RESULTADOS Y DISCUSIÓN}

\section{Evaluación microbiana}

Según la prueba de Tukey los valores de UFC g-1 de suelo de hongos aerobios totales aislados a partir de la rizosfera (Figura 1), permitieron organizar los tratamientos en cuatro grupos diferentes entre sí $(P<0.01)$, pero homogéneos dentro del grupo $(P>0.01)$ (grupo a: T7; grupo b: T5, T6 y T8, grupo c: T0, T2 y T4; grupo d: T1 y T3). El comportamiento a nivel de las muestras tomadas de suelo (Figura 1), presentó una tendencia similar, repartiendo los tratamientos en cuatro grupos diferentes $(P<0.01)$, de magnitud promedia de $\mathrm{UFC}^{-1}$ de suelo (grupo a: T6 y T7; grupo b: T5 y T8, grupo c: T0, T2 y T4; grupo d: T1 y T3). Sobresale el hecho de que en ambos casos el grupo con los valores más bajos de UFC g-1 de suelo se formó en los tratamientos T1 y T3. Para las bacterias aerobias aisladas en la rizosfera, los tratamientos se organizaron igualmente en cuatro grupos con promedios de UFC g ${ }^{-1}$ de suelo diferentes $(P<0.01)$ entre ellos (grupo a: T7, grupo b: T6 y T8; grupo c: T5, grupo d: T0, T1, T2, T3 y T4) (Figura 2). En el caso de las muestras de suelo, las UFC $\mathrm{g}^{-1}$ de suelo de bacterias, su comportamiento fue similar, dando lugar a la conformación de cuatro grupos (grupo a: T7, grupo b: T8, grupo c: T5; grupo d: T0, T1, T2, T3 y T4) (Figura 2). Los valores UFC $\mathrm{g}^{-1}$ se suelo de actinomicetes aerobios aislados tanto de la rizosfera como del suelo (Figura 3), permitieron ser re- partidos de manera similar los tratamientos en dos grupos, con promedios diferentes $(P<0.01)$ entre ellos pero homogéneos dentro de cada grupo $(P>0.01)$ (grupo a: T5, T6, T7 y T8 con mayor promedio; grupo b: T0, T1, T2, T3 y T4, con menores valores).

Para los hongos, bacterias y actinomicetos anaerobios estrictos o facultativos totales no se observaron diferencias significativas $(P<0.01)$, entre todos los tratamientos, con respecto al control $\mathrm{T} 0$, tanto a nivel de suelo como de rizosfera.

En general la población microbiana aeróbica evaluada se vio favorecida por los tratamientos que usaron fuentes orgánicas solas o en combinación con fungicidas (tratamientos T5 a T8). A su vez el tratamiento T8 presentó una capacidad de reducción de la enfermedad mayor representada por un menor valor del área bajo la curva del progreso de la enfermedad (Figura 4) en comparación con T0 (Figura 4). Este resultado sugiere un efecto directo de estos tipos de microorganismos, dado el mayor nivel de enfermedad observado, bajo los tratamientos con solo fungicidas (T1, T2, T3 y T4) (Figura 4) y la reducción observada en la microbiota (Figura 1, 2 y 3). En la literatura los grupos de hongos y bacterias han sido asociados como antagonistas de P. cinnamomi en suelo, actuando bajo diferentes mecanismos (Broadbent \& Baker, 1974; Maas \& Kotzé, 1990; Downer et al., 2001; Pérez, 2008). Menos estudiado ha sido el papel individual de los actinomicetos sobre P. cinnamomi, donde You et al. (1996) plantean que en aguacate, su acción antagonista se ve favorecida por las adiciones de materia orgánica y diferentes tipos de mantillo orgánico.

En las Figuras 1, 2 y 3 se observa que las poblaciones de microorganismos aerobios aislados son mayores en la rizosfera que en el suelo, mostrando que la dinámica microbiana varía en la medida que se aumenta la distancia desde la rizosfera. Este fenómeno se da porque las poblaciones de microbios están altamente influenciadas por sustancias o exudados producidos por las raíces, los cuales sirven como fuente energética y pueden llegar a inducir incluso cambios de $\mathrm{pH}$, disponibilidad de sustratos, nutrientes y factores de crecimiento microbiano moldeando de esta manera las especies y las cantidades existentes (Marschner et al., 2004).

Gracias a la prueba de Tukey la actividad microbiana total (Figura 5), permitió congregar los ocho tratamientos y su control en tres grupos con base en los valores promedio de $\mathrm{CO}_{2}$ liberado $(P<0.01)$. El grupo a), en el cual se ubicó T7; el grupo b) comprendido por T5, T6 y T8 y el grupo c), por T0, T1, T2, T3 y T4. En los tratamientos que recibieron alguna fuente de materia orgánica (T5, T6, T7 y T8) se observó una mayor actividad de la microbiota del suelo, expresada como producción de $\mathrm{CO}_{2}$, coincidiendo con una mayor población microbiana (Figura 1, 2 y 3) y 
una disminución de la enfermedad (Figura 4). La mayor cantidad producida de $\mathrm{CO}_{2}\left(>433 \mathrm{mg} \mathrm{kg}^{-1}\right)$, posiblemente se debe a la oxidación de residuos de plantas, exudados y de materia orgánica presente en el suelo (Machulla, 2003), consecuencia de las adiciones realizadas en los tratamientos T5, T6, T7 y T8. Estos resultados coinciden con los trabajos realizados por Vidales \& Alcantar (1999) y Costa et al., (2000), quienes encontraron una mayor actividad microbiana, cuando realizaron adiciones de materiales orgánicos al suelo, compuestos por estiércoles y harina de alfalfa.
El tratamiento con mayor nivel de diversidad $(P<0,01)$ medido por el índice de Shannon, fue T7, seguido de T5, T6, T8, después en un nivel intermedio T4, T3, T2 y los valores más bajos fueron para T1 y T3 (Tabla 1). Con el índice de Equidad microbiana (Equitability), se obtuvieron los valores más altos $(P<0.01)$ para T7, T6, T8 y T5, seguido de T1, T2 T3, T4 $(P>0.01)$ (Tabla 1). A nivel de la información entregada por el índice de Riqueza (Margalet), esta no difirió mucho de la entregada por Equidad microbiana (Equitability), solo con la diferencia estadísticamente significativa $(P<0.01)$, que se presentó entre T4 y T1 (Tabla 1).

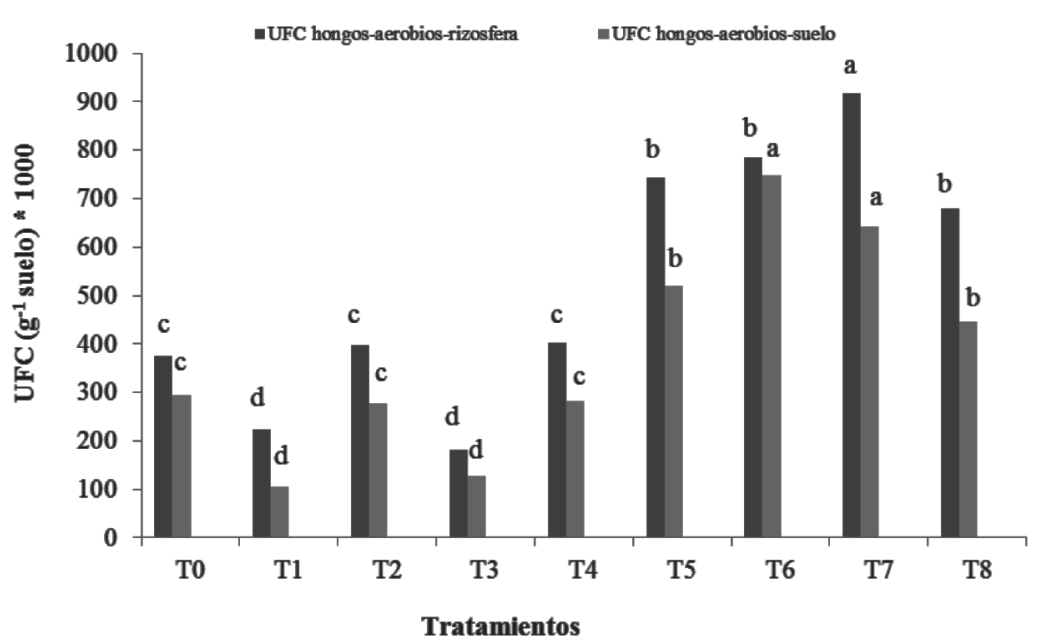

Figura 1. Unidades formadoras de colonia $\mathrm{UFC} \mathrm{g}^{-1}$ de suelo, de hongos aerobios aislados del suelo y de la rizosfera asociadas a ocho estrategias de manejo de la marchitez del aguacate (P. cinamomi RANDS).T0: control (plantas enfermas). T1: Ridomil Gold® (metalaxyl + mancozeb). T2: Agrifos ${ }^{\circledR}$ (fosfito de potasio). T3:T1 y T2. T4: silicato de potasio (20.5\% $\left.\mathrm{SiO}_{2}, 8.0 \% \mathrm{~K}_{2} \mathrm{O}\right)$. T5: mantillo orgánico. T6: sustrato compostado. T7: T4+T5+T6. T8: T1+T2+ T4+T5+T6. El valor de cada columna representa el promedio de cinco repeticiones, letras distintas en las columnas de un mismo color significan diferencias estadísticas entre los tratamientos para cada grupo de microorganismos obtenidos de la rizosfera o del suelo, evaluados mediante la prueba de Tukey $(P<0.01)$.

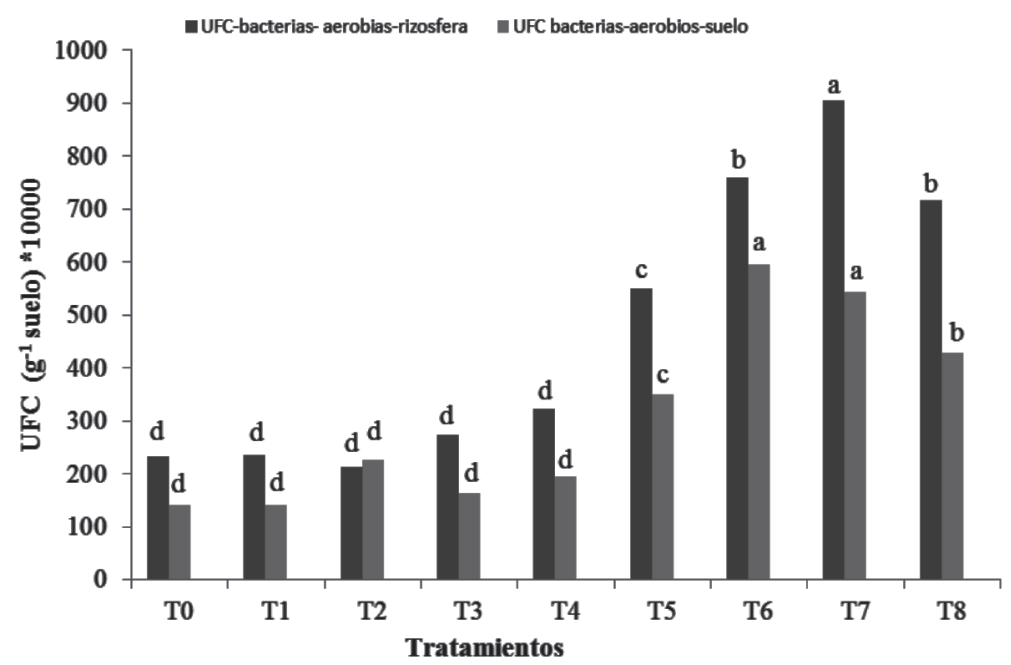

Figura 2. Unidades formadoras de colonia $\mathrm{UFC}^{-1}$ de suelo, de bacterias aeróbicas aisladas del suelo y de la rizosfera asociadas a ocho estrategias de manejo de la marchitez del aguacate. T0: control (plantas enfermas). T1: Ridomil Gold® (metalaxyl + mancozeb). T2: Agrifos ${ }^{\circledR}$ (fosfito de potasio). T3:T1 y T2. T4: silicato de potasio $\left(20.5 \% \mathrm{SiO}_{2}, 8.0 \% \mathrm{~K}_{2} \mathrm{O}\right)$. T5: mantillo orgánico. T6: sustrato compostado. T7: T4+T5+T6. T8: $\mathrm{T} 1+\mathrm{T} 2+\mathrm{T} 4+\mathrm{T} 5+\mathrm{T} 6$. El valor de cada columna representa el promedio de cinco repeticiones, letras distintas en las columnas de un mismo color significan diferencias estadísticas entre los tratamientos para cada grupo de microorganismos obtenidos de la rizosfera o del suelo, evaluados mediante la prueba de Tukey $(P<0.01)$. 
Los resultados encontrados para los sistemas de manejo de la marchitez en campo causada por P. cinnamomi, permitieron evidenciar un efecto negativo de los fungicidas asperjados al suelo (metalaxyl + mancozeb), en los tratamientos T1 y T3, respecto al control T0 (Figura 1), sobre la población de hongos evaluados en la rizosfera y en el suelo. Estos hallazgos contrastan con lo reportado por Valenzuela et al. (1985) quienes encontraron que aplicaciones de metalxyl no tuvieron efecto sobre la microbiota del suelo. En T8 se observó una disminución del efecto negativo del producto químico, posiblemente debido a la adición de materia orgánica, la cual promovió el establecimiento de la población microbiana no solo de hongos sino también de bacterias y actinomicetos y la disminución de la enfermedad. You \& Sivasithamparam,
(1995) reportaron que la materia orgánica tuvo un efecto negativo sobre la sobrevivencia de $P$. cinnamomi, observando lisis de hifas y esporangios abortivos, como consecuencia del aumento de la biomasa microbiana total. Otros autores también reportan el uso de materia orgánica y coberturas vegetales con excelentes resultados en el manejo de P. cinnamomi (Costa et al., 2000; Vidales \& Alcantar 1999; Richter et al., 2011; Bonilla et al., 2012).

\section{Grupos funcionales}

El valor encontrado para UFC $\mathrm{g}^{-1}$ de suelo promedio formadas de Pseudomonas spp. fluorescentes y de Trichoderma spp., permitieron organizar similarmente los efectos de los tratamientos en dos grupos diferentes $(P<0.01)$, T6, T7 y T8 con mayores niveles de estos dos

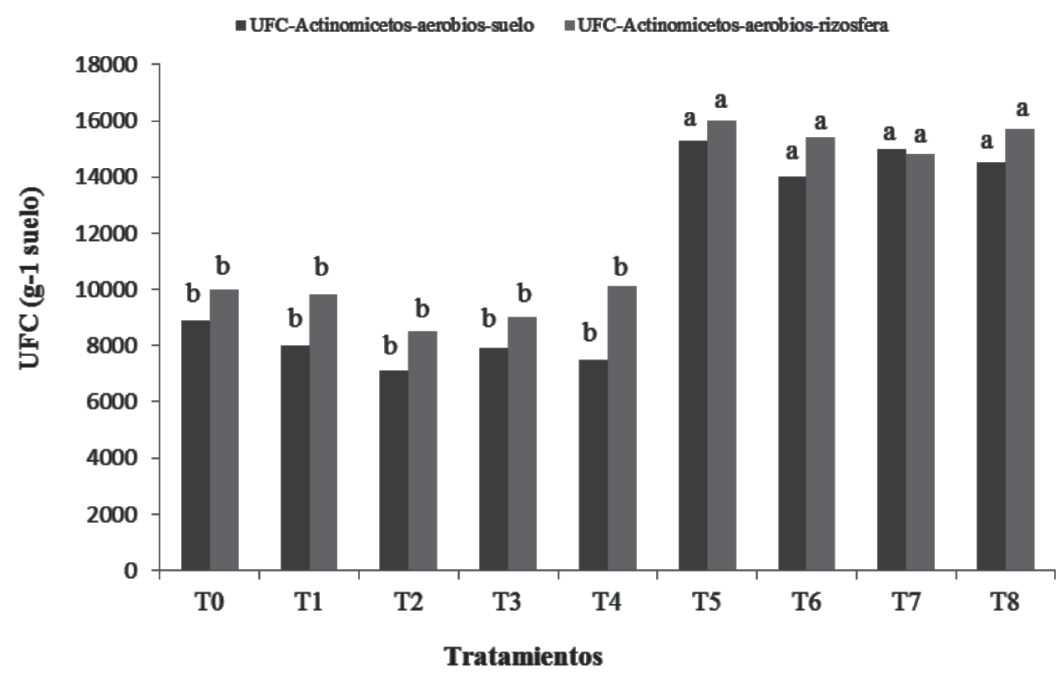

Figura 3. Unidades formadoras de colonia $\mathrm{UFC}^{-1}$ de suelo, de actinomicetos aeróbicos aislados del suelo y de la rizosfera asociado a ocho estrategias de manejo de la marchitez del aguacate. T0: control (plantas enfermas). T1: Ridomil Gold® (metalaxyl + mancozeb). T2: Agrifos ${ }^{\circledR}$ (fosfito de potasio). T3:T1 y T2. T4: silicato de potasio $\left(20.5 \% \mathrm{SiO}_{2}, 8.0 \% \mathrm{~K}_{2} \mathrm{O}\right)$. T5: mantillo orgánico. T6: sustrato compostado. T7: $\mathrm{T} 4+\mathrm{T} 5+\mathrm{T} 6$. $\mathrm{T} 8$ : $\mathrm{T} 1+\mathrm{T} 2+\mathrm{T} 4+\mathrm{T} 5+\mathrm{T} 6$. El valor de cada columna representa el promedio de cinco repeticiones, letras distintas en las columnas de un mismo color significan diferencias estadísticas entre los tratamientos para cada grupo de microorganismos obtenidos de la rizosfera o del suelo, evaluados mediante la prueba de Tukey $(P<0.01)$.

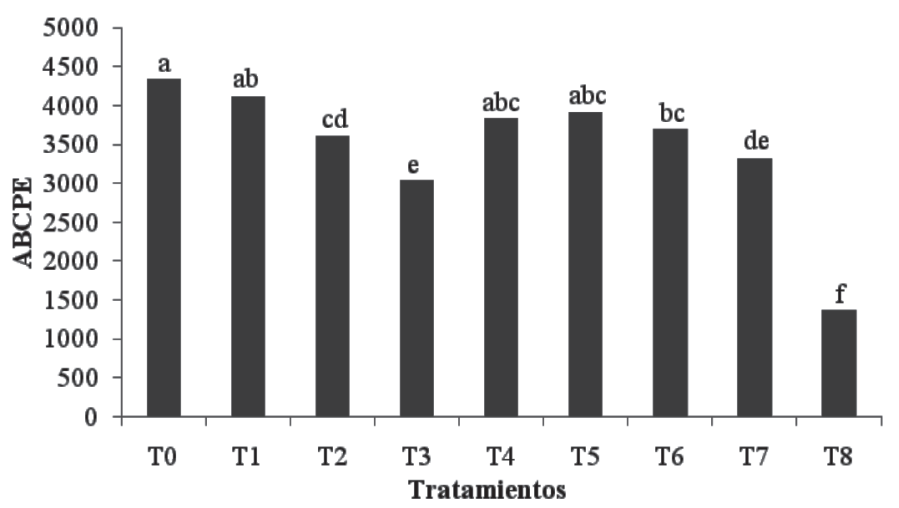

Figura 4. Área bajo la curva del progreso de la enfermedad (ABCPE), construida mediante la escala de Coffey (1991). T0: control (plantas enfermas). T1: Ridomil Gold® (metalaxyl + mancozeb). T2: Agrifos® (fosfito de potasio). T3:T1 y T2. T4: silicato de potasio $\left(20.5 \% \mathrm{SiO}_{2}, 8.0 \% \mathrm{~K}_{2} \mathrm{O}\right)$. T5: mantillo orgánico. T6: sustrato compostado. T7: T4+T5+T6. T8: T1+T2+ T4+T5+T6. El valor de cada columna representa el promedio de cinco repeticiones, letras distintas en las columnas significan diferencias estadísticas entre los tratamientos, evaluados mediante la prueba de Tukey $(P<0.01)$. 
grupos de microorganismos y T0, T1, T2, T3, T4 y T5 con valores más bajos (Tabla 2). Las BAFES categorizó el efecto de los tratamientos en 3 grupos diferentes $(P<0.01)$ (grupo a: T0, T1, T3, T4; grupo b: T2, T5, T6, T8; grupo c: T7), donde este ultimo presento una mayor población (Tabla 2), mientras que los microorganismos degradadores de celulosa (CL), permitieron identificar dos grupos (grupo a: T5, T7, T8; grupo b: T0, T1, T2, T3, T4 y T6) (tabla 2). Ninguno de los tratamientos evaluados estimuló significativamente $(P<0,01)$, la presencia de microorganismos proteolíticos, amilolíticos, quitinolíticos, solubilizadores de fósforo y fijadores asimbióticos de nitrógeno (Tabla 2).

La mayor cantidad de bacterias Pseudomonas spp. fluorescentes, cuantificadas para los tratamientos T6, T7 y T8, podría contribuir en parte a explicar el efecto observado de la reducción de la enfermedad (Figura 4), que que Yang et al. (2001) encontraron que Pseudomonas fluorescens, estuvo asociada a la supresión de $P$. cinnamomi en aguacate. En investigaciones similares, donde los suelos se definieron como supresivos para este patógeno en aguacate, estas bacterias fueron aisladas en gran número, por lo cual se consideraron como componente activo del efecto antagonista (Broadbent \& Baker, 1974; Maas \& Kotze, 1990). Las bacterias del genero Pseudomonas, son reconocidas como promotoras del crecimiento vegetal, por la capacidad de colonizar los sistemas radicales de las plantas, promover el crecimiento al sintetizar reguladores hormonales como las auxinas y giberelinas, e indirectamente juegan un papel importante en la disminución o prevención de fitopatógenos, ya que activan la resistencia sistémica inducida (RSI) (Bakker et al., 2003; Lugtenberg \& Kamilova, 2009).

En T6, T7 y T8, la adición de materia orgánica aumentó las poblaciones de Trichoderma spp., (Tabla 2),

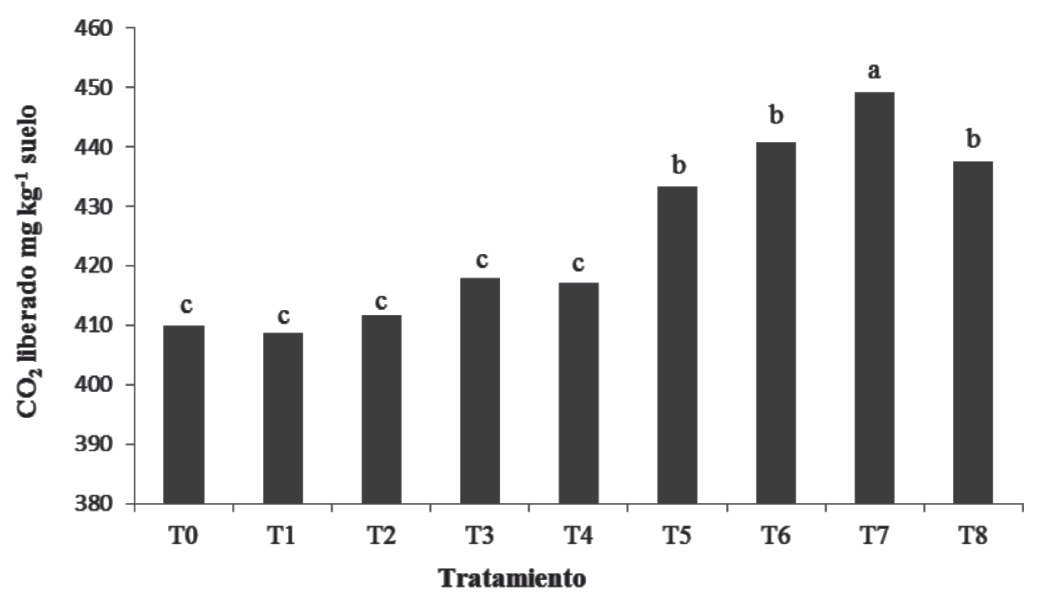

Figura 5. $\mathrm{CO}_{2}$ liberado $\left(\mathrm{mg} \mathrm{kg}^{-1}\right.$ suelo) asociado a ocho estrategias de manejo de la marchitez del aguacate. T0: control (plantas enfermas). T1: Ridomil Gold® (metalaxyl + mancozeb). T2: Agrifos® (fosfito de potasio). T3:T1 y T2. T4: silicato de potasio $\left(20.5 \% \mathrm{SiO}_{2}, 8.0 \% \mathrm{~K}_{2} \mathrm{O}\right)$. T5: mantillo orgánico. T6: sustrato compostado. T7: T4+T5+T6. T8: T1+T2+ T4+T5+T6. El valor de cada columna representa el promedio de cinco repeticiones, letras distintas en las columnas de un mismo color significan diferencias estadísticas entre los tratamientos para cada grupo de microorganismos, evaluados mediante la prueba de Tukey $(P<0.01)$.

Tabla 1. Efecto de ocho estrategias de manejo de la marchitez del aguacate en los índices poblacionales totales de equidad, diversidad y riqueza microbiana, evaluados en la rizosfera y suelo de árboles adultos

\begin{tabular}{lccc}
\hline Tratamiento & $\begin{array}{c}\text { Equidad microbiana } \\
\text { (equitability) }\end{array}$ & $\begin{array}{c}\text { Diversidad microbiana } \\
\text { (Shannon) }\end{array}$ & $\begin{array}{c}\text { Riqueza microbiana } \\
\text { (Margalet) }\end{array}$ \\
\hline T0 & $3.672 \mathrm{a}$ & $1.616 \mathrm{~b}$ & $1.622 \mathrm{ab}$ \\
T1 & $3.32 \mathrm{a}$ & $1.262 \mathrm{a}$ & $1.34 \mathrm{a}$ \\
T2 & $3.81 \mathrm{a}$ & $1.6854 \mathrm{~b}$ & $1.698 \mathrm{ab}$ \\
$\mathrm{T} 3$ & $3.1 \mathrm{a}$ & $1.216 \mathrm{~b}$ & $1.604 \mathrm{ab}$ \\
$\mathrm{T} 4$ & $3.32 \mathrm{a}$ & $1.744 \mathrm{~b}$ & $1.974 \mathrm{~b}$ \\
T5 & $5.94 \mathrm{~b}$ & $2.49 \mathrm{~cd}$ & $2.852 \mathrm{c}$ \\
T6 & $5.06 \mathrm{~b}$ & $2.484 \mathrm{~cd}$ & $2.874 \mathrm{c}$ \\
T7 & $6.03 \mathrm{~b}$ & $2.5144 \mathrm{~d}$ & $3.266 \mathrm{c}$ \\
T8 & $5.84 \mathrm{~b}$ & $2.474 \mathrm{~cd}$ & $2.724 \mathrm{c}$ \\
\hline
\end{tabular}

T0: control (plantas enfermas). T1: Ridomil Gold® (metalaxyl + mancozeb). T2: Agrifos® (fosfito de potasio). T3:T1 y T2. T4: silicato de potasio $\left(20.5 \% \mathrm{SiO}_{2}, 8.0 \% \mathrm{~K}_{2} \mathrm{O}\right)$. T5: mantillo orgánico. T6: sustrato compostado. T7: T4+T5+T6. T8: T1+T2+ T4+T5+T6. El valor para cada columna y fila es el promedio de cinco repeticiones, donde letras distintas significan diferencias estadísticas entre los distintos tratamientos evaluados mediante la prueba de Tukey $(P<0.01)$. 
Tabla 2. Impacto de ocho estrategias de manejo de la marchitez del aguacate sobre grupos microbianos funcionales (UFC $\mathrm{g}^{-1}$ suelo)

\begin{tabular}{lcccccccc}
\hline Tratamiento & Trichoderma spp & $\begin{array}{c}\text { Pseudomonas spp. } \\
\text { fluorescente }\end{array}$ & BAFE & CL & AM & PT & SP & FN \\
\hline T0 & $36 \mathrm{~b}$ & $5.2 \times 10^{2} \mathrm{~b}$ & $200 \mathrm{a}$ & $60 \mathrm{~b}$ & $250 \mathrm{a}$ & $25 \mathrm{a}$ & $100 \mathrm{a}$ & $140 \mathrm{a}$ \\
T1 & $26 \mathrm{~b}$ & $4.8 \times 10^{2} \mathrm{~b}$ & $210 \mathrm{a}$ & $58 \mathrm{~b}$ & $243 \mathrm{a}$ & $22 \mathrm{a}$ & $115 \mathrm{a}$ & $167 \mathrm{a}$ \\
T2 & $28 \mathrm{~b}$ & $4.9 \times 10^{2} \mathrm{~b}$ & $530 \mathrm{~b}$ & $74 \mathrm{~b}$ & $248 \mathrm{a}$ & $28 \mathrm{a}$ & $98 \mathrm{a}$ & $153 \mathrm{a}$ \\
T3 & $30 \mathrm{~b}$ & $5.2 \times 10^{2} \mathrm{~b}$ & $190 \mathrm{a}$ & $68 \mathrm{~b}$ & $246 \mathrm{a}$ & $19 \mathrm{a}$ & $118 \mathrm{a}$ & $139 \mathrm{a}$ \\
T4 & $33 \mathrm{~b}$ & $5.4 \times 10^{2} \mathrm{~b}$ & $250 \mathrm{a}$ & $75 \mathrm{~b}$ & $254 \mathrm{a}$ & $24 \mathrm{a}$ & $132 \mathrm{a}$ & $145 \mathrm{a}$ \\
T5 & $35 \mathrm{~b}$ & $5.8 \times 10^{2} \mathrm{~b}$ & $570 \mathrm{~b}$ & $200 \mathrm{a}$ & $252 \mathrm{a}$ & $20 \mathrm{a}$ & $139 \mathrm{a}$ & $178 \mathrm{a}$ \\
T6 & $50 \mathrm{a}$ & $7.1 \times 10^{3} \mathrm{a}$ & $615 \mathrm{~b}$ & $80 \mathrm{~b}$ & $250 \mathrm{a}$ & $26 \mathrm{a}$ & $136 \mathrm{a}$ & $151 \mathrm{a}$ \\
T7 & $62 \mathrm{a}$ & $8.4 \times 10^{3} \mathrm{a}$ & $945 \mathrm{c}$ & $190 \mathrm{a}$ & $253 \mathrm{a}$ & $21 \mathrm{a}$ & $119 \mathrm{a}$ & $156 \mathrm{a}$ \\
T8 & $57 \mathrm{a}$ & $7.9 \times 10^{3} \mathrm{a}$ & $538 \mathrm{~b}$ & $185 \mathrm{a}$ & $252 \mathrm{a}$ & $19 \mathrm{a}$ & $113 \mathrm{a}$ & $168 \mathrm{a}$ \\
\hline
\end{tabular}

BAFE: bacterias aeróbicas formadoras de espora. CL microorganismos celulíticos. AM: microorganismos amilolíticos. PT: microorganismos proteolíticos. SP microorganismos, solubilizadores de fosfato. FN microorganismos, fijadores asimbioticos de nitrógeno. T0: control (plantas enfermas). T1: Ridomil Gold® (metalaxyl + mancozeb). T2: Agrifos® (fosfito de potasio). T3: T1 y T2. T4: silicato de potasio (20.5\% $\left.\mathrm{SiO}_{2}, 8.0 \% \mathrm{~K}_{2} \mathrm{O}\right)$. T5: mantillo orgánico. T6: sustrato compostado. T7: T4+T5+T6. T8: T1+T2+ T4+T5+T6. E1 valor para cada columna y fila es el promedio de cinco repeticiones, donde letras distintas significan diferencias estadísticas entre los distintos tratamientos evaluados mediante la prueba de Tukey $(P<0.01)$.

coincidiendo con la reducción de la enfermedad (Figura 4). Estudios previos han mostrado que la acción de Trichoderma virens y Trichoderma harzianum, disminuyen la viabilidad de esporangios de P. cinnamomi, cuando se realiza adición de materia orgánica, potenciando los mecanismos de supresión, sobre la fase saprofítica de P. cinnamomi (McLeod et al., 1995; Chambers \& Scott, 1995; Costa et al., 2000).

Los microorganismos degradadores de celulosa (Tabla 2), se encontraron en mayor cantidad en los tratamientos T5, T7 y T8, resultados que indican que las adiciones de mantillo orgánico, tienen un efecto positivo sobre esta población de microorganismos. Se considera que la actividad de la celulosa es muy alta en el mantillo orgánico en descomposición y puede correlacionarse con la disminución de Phytophthora sp., posiblemente por la degradación de las paredes celulares celulósicas de los oomycetos (Downer et al., 2001; Richter et al., 2011).

El mayor nivel de BAFES cuantificadas (Tabla 2), también se asoció con aquellos tratamientos que lograron reducir la enfermedad (Figura 4). Algunas especies BAFES del género Bacillus spp., como Bacillus subtilis, Bacillus azotoformans, Bacillus megaterium, Bacillus spp, Bacillus mycoides, han presentado antagonismo hacia $P$. cinnamomi en aguacate. Posiblemente el fenotipo observado en los tratamientos también se deba en parte a la contribución de las BAFEs en aspectos como el incremento en el crecimiento de las plantas, por mecanismos como la fijación de nitrógeno, fósforo y potasio, solubilización de fosfato y otros nutrientes, o por la producción de sideróforos o antibióticos para la supresión de P. cinnamomi (Broadbent \& Baker, 1974; Maas \& Kotzé 1990; Duvenhage et al., 1991).

T7 fue el tratamiento que permitió el establecimiento de mayor cantidad de microorganismos aeróbicos, alta actividad microbiana en el suelo, mejor estabilidad a nivel de la población microbiana, mayores niveles de Pseudomonas spp. fluorescentes, BAFES y Trichoderma spp., y reducción de la enfermedad a un nivel solo superado por los tratamientos que usaron combinadamente fosfito de potasio y metalaxyl + mancozeb (Ridomil Gold®) (T3 y T8). Para seleccionar el mejor tratamiento, no solo se debe considerar el parámetro de nivel de enfermedad, sino varios efectos positivos adicionales que se obtienen por la adición de materia orgánica en el suelo, algunos a largo plazo, como la proliferación y re-colonización de microorganismos en el suelo, la nutrición de la planta, las propiedades físicas y químicas del suelo, entre muchos otros.

\section{CONCLUSIONES}

Las adiciones realizadas al suelo de minerales y materia orgánica, favorecen la microbiota del suelo, incrementando la población de Pseudomonas spp. fluorescentes, BAFES , celulolíticos y Trichoderma spp., mejorando además el manejo de $P$. cinnamomi.

Las prácticas de control de la marchitez basadas en productos de origen químico, no favorecen y por el contrario pueden tener un efecto deletéreo sobre las poblaciones de microorganismos benéficos en el suelo.

\section{AGRADECIMIENTOS}

Los autores expresan su agradecimiento al señor Carlos Noreña propietario de la finca en donde se realizó el experimento, por la colaboración recibida. Al profesor de la Universidad Nacional de Colombia sede Medellín Walter Osorio y a la candidata a Master en Geomorfología y Suelos Laura Osorno por la asesoría y ayuda en el trabajo. 


\section{REFERENCIAS}

Anderson J \& Domsch K (1978) A physiological method for the quantitative measurement of microbial biomass in soils. Soil Biology and Biochemistry, 10:215-221.

Ariena H, Van Bruggen A, Semenov M, Van Diepeningen A, De Vos O \& Blok W (2006) Relation between soil health, wavelike fluctuations in microbial populations, and soil-borne plant disease management. European Journal of Plant Pathology, 115:105-122.

Bakker P, Ran L, Pieterse C \& van Loon L (2003) Understanding the involvement of rhizobacteria-mediated induction of systemic resistance in biocontrol of plant diseases. Canadiam journal plant patholology, 25:05-09.

Broadbent P \& Baker K (1974) Behaviour of Phytophthora cinnamomi in soils suppressive and conducive to root rot. Australian Journal of Agricultural Research, 25:121-137.

Bonilla N, Cazorla F, Martínez M, Hermoso J, González J, Gaju N, Landa B \& Vicente A (2012) Organic amendments and land management affect bacterial community composition, diversity and biomass in avocado crop soils. Plant soil, 357:215-226.

Buckley D \& Schmidt T (2003) Diversity and dynamics of microbial communities in soils from agro-ecosystems. Environment microbiology, 5:441-452.

Coffey M (1991) Cause and diagnosis. Avocado root rot. California Grower, 15:22-23.

Costa J, Menge J \& Casale W (2000) Biological control of Phytophthora root rot of avocado with microorganisms grown in organic mulches. Brazilian Journal of Microbiology, 31:239246

Chambers S \& Scott E (1995) In vitro antagonism of Phytophthora cinnamomi and P. citricola by isolates of Trichoderma spp. and Gliocladium virens. Journal of Phytopathology, 143:471-477.

Downer A, Menge J \& Pond E (2001) Effects of cellulytic enzymes on Phytophthora cinnamomi. Phytopathology, 91:839-846.

Dobereiner J \& Day J (1976) Associative symbioses in tropical grasses: characterization of microorganisms and dinitrogenfixing sites. In: Proceedings of the $1^{\text {st }}$ international symposium on nitrogen fixation. Pullman, Washington State University Press. p.518-538.

Duvenhage J, Kotze J \& Maas E (1991) Suppressive soils and biological control of Phytophthora root rot. South African Avocado Growers Association Yearbook, 14:06-11.

Girvan M, Bullimore J, Ball A, Pretty J \& Osborn A (2004) Responses of active bacterial and fungal communities in soils under winter wheat to different fertilizer and pesticide regimens. Applicate Enviroment Microbiology, 70:2692-2701.

Hammer $\varnothing$, Harper D \& Ryan P (2001) PAST: paleontological statistics software package for education and data analysis. Palaeontologia Electronica, 4:01-09.

Hardham AR (2005) Phytophthora cinnamomi. Molecular Plant Pathology, 6:589-604

Holdridge LR (1967) Life Zone Ecology. Tropical Science Center. San José, Costa Rica. 500p.

King E, Ward M \& Raney D (1954) Two simple media for demonstration of pyocyanin and fluorescin. Journal laboratory clinical medical, 44:301-307.

Lugtenberg B \& Kamilova F (2009) Plant-Growth-Promoting Rhizobacteria. Annual review microbiological, 63:541-556.

Madigan M, Martinko J \& Parker J (2004) Brock. Biología de los microorganismos. 10a ed. Madrid, Pearson Education. 1096p.
Madden L, VHughes G \& van den Bosch F (2007) The Study of Plant Disease Epidemics, APS Press, St. Paul. 500 p

McLeod A, Labuschagne N \& Kotze J (1995) Evaluation of Trichoderma for biological control of avocado root rot in bark medium artificially infested with Phytophthora cinnamomi. Yearbook of the South African Avocado Growers' Association, 18:32-37.

Marschner P, Crowley D \& Hong-Yang C (2004) Development of specific rhizosphere bacterial communities in relation to plant species, nutrition and soil type. Plant and Soil, 261:199-208.

Machulla G (2003) Soil microbial indicators and their environmental significance. Journal soils sediments, 3: 229246.

Maas E \& Kotzé J (1990) The effect of bacteria on root rot severity caused by Phytophthora cinnamomi. South africa avocado Growers association yearbook, 13:65-66.

Osorio N \& Habte M (2001) Synergistic Influence of an arbuscular mycorrhizal fungus and a $\mathrm{P}$ solubilizing fungus on growth and $\mathrm{P}$ uptake of Leucaena leucocephala in an oxisol. Arid Land Research and Management 153:263-274.

Pérez M (2008) Significant Avocado Diseases Caused by Fungi and Oomycetes. The European Journal of Plant Science and Biotechnology, 21:01-24.

Porras M, Barrau C \& Romero F (2007) Effects of soil solarization and Trichoderma on strawberry production. Crop Protection, 26:782-787

Ramírez CA (2005) Aislamiento y evaluación de rizobacterias con potencial biocontrolador y promotor de crecimiento en plantas en banano. Tesis de Maestría. Universidad Nacional de Colombia, Medellín. 169p.

Richter B, Ivors K, Shi W \& Benson DM (2011) Cellulase activity as a mechanism for suppression of Phytophthora root rot in mulches. Phytopathology, 101:223-230.

Simon A \& Ridge EH (1974) The use of ampicillin in a simplified selective Medium for the isolation of Fluorescent Pseudomonads. Journal applicate bacterial, 37:459-460.

Valenzuela J, Téliz D, García R \& Salazar S (1985) Manejo integrado de la marchitez (Phytophthora cinnamomi) del aguacatero en Atlixco, Puebla. Revista Mexicana de Fitopatología, 3:1830 .

Vidales J \& Alcantar J (1999) Acción de la solarización y de la materia orgánica en el control de la marchitez (Phytophthora cinnamomi Rands), del aguacate (Persea americana Mill cv Hass). Revista Chapingo serie horticultura, 5:255-259.

Wood P (1980) Specify in the interactions of direct dyes with polysaccharides. Carbohydrate research, 85:271-287.

Yang C, Crowley D \& Menge J (2001) 16S rDNA engerprinting of rhizosphere bacterial communities associated with healthy and Phytophthora infected avocado roots. Microbiology Ecology, 35:129-136

You M \& Sivasithamparam K (1995) Changes in microbial populations of an avocado plantation mulch suppressive of Phytophthora cinnamomi. Applied Soil Ecology, 2:33-43.

You M, Sivasithamparam K \& Kurtboke D (1996) Actinomycetes in organic mulch used in avocado plantations and their ability to suppress Phytophthora cinnamomi. Biology and Fertility of Soils, 22:237-242.

Rev. Ceres, Viçosa, v. 60, n.6, p. 811-819, nov/dez, 2013 